\title{
水电大坝施工中水下混凝土施工技术的有效应用
}

季林

四川子禾工程技术有限公司

DOI:10.32629/hwr.v3i4.2032

[ 摘 要] 水下混凝土是在普通混凝土中添加了适量的絮凝剂,其具有十分理想的流动性和抗分散性,水下混凝土不易出现离 析和分层的问题, 可有效提高工程施工质量。本文就将主要分析水电大坝施工中水下混凝土施工技术的有效应用, 以供参考。 [关键词] 水电大坝施工; 水下混凝土; 流动性

水下混凝土也被人们称为水下浇筑混凝土。其主要借助 施工中较为理想的隔水设备完成工程建设。利用水下不易分 散的混凝土可保证水下混凝土灌注的质量。在混凝土当中加 入絮凝剂之后, 在相对较短的时间内可将混凝土直接放入水 中, 施工后可有效避免水环境对工程质量产生不利影响。

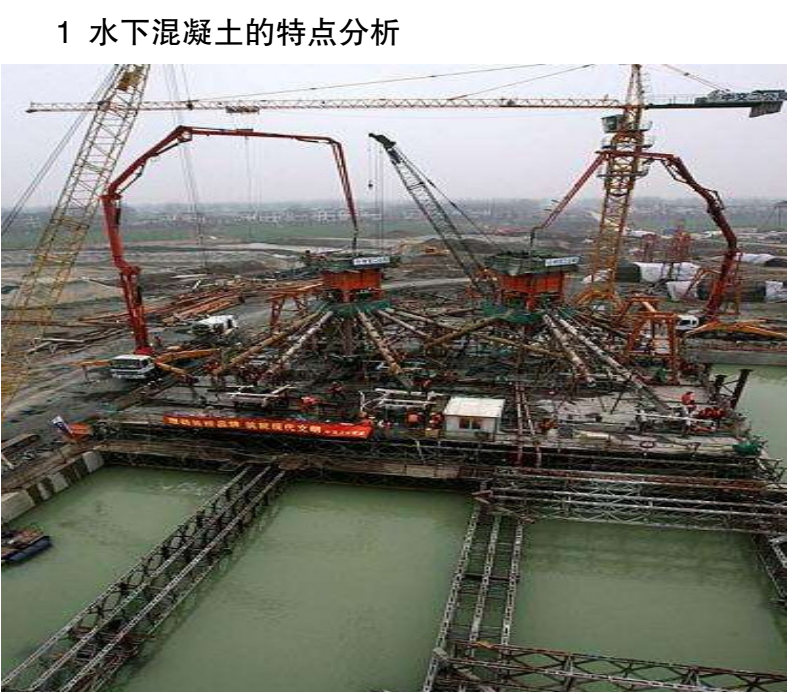

图 1 水下混凝土施工示意图

1. 1 较强的流动性

水下混凝土浇筑施工中无需借助外力振捣, 只需利用钢 筋的缝隙便可保证填缝效果, 形成均匀的自密实结构。同时, 在工程施工过程中可实现自流平, 不泌水, 不离析。试验表明, 水下混凝土的扩展度可达到 $35-50 \mathrm{~cm}$, 已经超过了普通混凝 土的施工要求。利用标准的方法检验后发现水下混凝土的坍 落度可达 18-22cm, 满足了普通混凝土的施工要求。但是水 下混凝土的流动性会受到现场条件及施工方法的影响, 流动 性较好的混凝土施工性能也相对较好, 但是浇筑的过程中也 非常容易出现骨料下沉的问题。而流动性较小的混凝土水下 振捣的难度明显增大, 因此混凝土的密实度也会受到较大的 影响。

\section{2 良好的抗分散性}

水利工程施工中, 在摚拌混凝土时加入适量的絮凝剂可 减少混凝土拌和料的流失, 避免离析问题, 增强了混凝土的 抗冲刷能力。在科学篎选拌和物及水溶液 PH 值, 检验透光率
后可检验水下混凝土的抗分散能力。若 SCR 絮凝剂的掺量已 经大于水泥的重量时, 则其水溶液的 PH 值应在 8-10 之内, 透光率不得小于 $90 \%$ 。尽管拌和物在深度为 $40 \mathrm{~m}$ 的水中落下, 其抗分散性依然良好, 可始终保持混凝土配合比的稳定性, 从而在水下环境中依然可形成相对均匀的混凝土结构。

\section{3 较高的泌水性}

水下混凝土掺入絮凝剂后, 絮凝剂表面的活性物质会对 混凝土产生较为明显的作用, 进而使混凝土拌和物当中的粗 分散体系颗粒表面发生较大的变化, 体系中的分散颗粒与水 泥颗粒充分地结合在一起, 形成非常致密且稳定的网状结构, 最后形成新型的水下不易分散的混凝土结构。另外, 其也具 有非常好的泌水性能, 避免了混凝土发生离析问题。若掺入 的絮凝剂超过 $0.5 \%$, 通常情况下不会出现泌水的问题, 有效 增强了混凝土的保水性和粘稠性。专业检验显示, 絮凝剂是 一种具有良好安全性的保水材料, 其对人体无害, 因此可大 范围应用于水利工程建设当中。

\section{2 水利工程中水下混凝土的施工技术分析}

2.1 添加絮凝剂法

在工程建设中适度添加抗分离剂能够形成水下不分散 的混凝土结构, 同时也可显著增强其抗冲刷能力。在水下短 距离自由下落的过程中无需振捣就能够在水下自流平, 自密 实, 有效减轻了水环境污染, 缩短了工程的施工周期。再者, 其也是一种较为理想的水下混凝土浇筑施工方法。该方法施 工中, 混凝土的抗压强度要在 25-30MPa 之间, 但是该混凝土 的造价是普通混凝土的 1.5-2 倍。该混凝土在工程建设中得 到了较为广泛的应用, 利用导管或泵压的方式可有效减少水 环境对混凝土灌注的影响, 其可应用于标准较高的水污染防 治项目当中。

\section{2 泵压输送法}

泵压输送法施工中主要采用混凝土输送泵, 该设备可实 现混凝土输送和浇筑的同时完成, 且严格控制混凝土泵输送 混凝土的位置, 规定在 $30-40 \mathrm{~cm}$ 之间, 若距离过大, 则泵送的 阻力也会随之增大, 泵管的压力也会发生较大的变化, 十分 容易发生安全事故。若深度过小, 则就会出现反水现象, 所以 必须密切关注混凝土的流柱状态。在输送混凝土前要在输送 管中塞入海绵球, 之后方可原送, 确保输送水和混凝土管道 
相互分离, 实现输送管道的篎子与混凝土充分接触, 将管道 塞满。

另外, 在泵管设置的过程中应结合水下混凝土泵送过程 中的阻力, 防止管径过小导致管道弯曲问题。若混凝土输送 的过程中发生突然中断的问题, 则需将管子立刻插入到浇筑 的混凝土当中, 防止水分进入到输送管, 如浇筑的范围过大, 则可及时安排潜水员调整浇筑的位置。在完成洜压施工后, 要彻底清理混凝土泵, 避免混凝土泵水不合理排放, 严重影 响周边的水环境。

\section{3 装袋叠置法}

在工程施工中注意将透水纤维织物放入水下位置, 织物 袋中通常放入坞落度为 50-70mm 的混凝土混合物。带内所装 的物体应为袋子体积的三分之二, 纤维织物带需采用交替叠 放的方式。为了保证结构的稳定性可采取短钢筋插接的方式, 该方式成本较高, 但是结构十分稳定, 其主要应用于非侵蚀 环境。若与模袋混凝土技术有机结合可在河道护岸及航道整 治当中广泛应用。

\section{4 开底吊桶法}

开底吊桶方式可确保混凝土混合物与环境水的有效接 触, 规定混凝土坞落度在 $150 \mathrm{~mm}$ 左右。与开底吊桶方法相似, 水工混凝土施工中主要采用夯法和振法两种施工方式, 其均 是为了从岸边向水体当中涌来, 因此也被人们称为端进法。 这种方法一般应用于 $5 \mathrm{~m}$ 左右的水深当中, 且现场的施工环 境均需满足要求, 此时可适度降低混凝土的坍落度, 不断增 强混凝土的完整性和抗侵蚀性能。

在工程施工中, 要在罐体顶部的混凝土上覆盖帆布或防 水油布, 底部要沿着水下地面打开, 从而有效减少混凝土浇 筑过程中外力的负面影响。同时, 应采用吊机将吊罐放入水 中, 在混凝土浇筑施工中, 吊罐的底部应与浇筑板面保持较 近的距离, 并及时开启底门, 排除所有的混凝土, 然后将吊罐 直接带离混凝土面。最后, 要充分保证每批混凝土灌入水下 后均会在上一次灌注的混凝土顶部, 之后应用振动或振捣的 方式将混凝土拓展至水域部分。吊罐法通常采用雉形施工机 械, 在罐体的底部开弧, 从而强化混凝土排出的效果, 这一方 式可应用于水位相对较低, 且工程量较小的混凝土施工中, 其优势十分明显, 因此在工程建设中也得到了广泛的应用。

\section{5 垂直导管法}

垂直导管法一般采用密封管强的水下施工, 其通常是将 软体球放在混凝土的表面, 水下混凝土会将求顶向小球的周 围, 其主要可利用自身流动性的优势, 在导管的下端形成自 流平混凝土。坚管法施工中通常由混凝土管和料斗构成, 管 内的直径通常在 $25-30 \mathrm{~cm}$, 施工中, 针对已经浇筑的混凝土, 为了可有效保证更加顺利地从混凝土中拔出导管下端, 需要 确保导管当中具有充足的混凝土, 让其坍落度始终保持在
$30-50 \mathrm{~cm}$, 但是也要保证混凝土在水中自由下落。在水下混凝 土浇筑施工中, 填充漏斗应使用混凝土反复填充, 有效避免 混凝土倒流的问题。在混凝土浇筑施工前, 注意保证混凝土 和水处于分离状态, 浇筑前要将底盖打开, 同时将水中的导 管注满混凝土, 并将滑塞滑出管道, 防止充水问题, 且适度提 高混凝土在水中的落差, 提高混凝土施工的质量。

垂直管法通常应用于大型的工程和深水工程当中。垂直 管法在应用的过程中具有十分显著的优势, 其设备操作相对 简单, 灌注的效率较高, 而且相关人员也开发出了其他的方 法, 如柔性管法和液压阀法。其具有良好的完整性, 且不易受 到其他技术方法的限制。柔性管能够受到水压的作用自动关 闭, 可有效避免导管内变空和反水事故等问题, 水下的混凝 土施工方法还有很多, 其优点也十分明显, 因此可结合实际 加以应用。

\section{3 水下混凝土施工质量控制}

首先, 在水下混凝土浇筑施工中, 应当根据配合比的基 本要求选择施工的原材料, 并且合理应用搅拌机生产混凝土, 搅拌的时间不得少于 $3 \mathrm{~min}$, 拌好后的混凝土需从溜槽当中直 接滑落到运输船的吊罐当中, 之后再充分结合搅拌机容量将 新拌的混凝土运送到指定位置。其次, 混凝土的浇筑水域必 须为静水, 且保证临近混凝土浇筑场面的闸门处于关闭的状 态, 距离较远的闸门可及时打开, 以提高排水的质量, 有效规 避水流的冲刷作用, 在保改善排水系统运行质量的同时确保 混凝土质量。再次, 吊罐应利用吊机放入到水中, 操作人员要 以水面定位框来控制吊罐的位置, 且做好调试工作。如吊罐 的底部与水下的距离在 $40-80 \mathrm{~cm}$ 时, 则需及时打开吊罐底部 的门, 以实现水下混凝土的自由下落。待卸料工作结束后, 再缓慢提升吊罐, 从而规避对新浇混凝土的负面影响。最后, 在浇筑施工后, 需利用水下摄像机拍摄仓面的情况, 并且要 去水上监控人员科学利用图像检查仓面, 避免漏浇的问题。

\section{4 结束语}

结合上述内容可以看出, 在水电大坝施工中, 科学选取 水下混凝土施工方案, 采用合理的施工工艺和施工方法, 一 方面可有效改善工程的施工质量, 另一方面还可提高工程的 施工效率。因此有必要全面结合工程实际, 选择最为合适的 施工方法, 以此增大工程施工的安全系数, 延长水电大坝的 使用寿命。

\section{[参考文献]}

[1] 梁柱长.水电大坝施工中水下混凝土施工技术的应 用[J].建材与装饰,2017,(11):258-259.

[2]张瑞. 水电站大坝上游围堰水下混凝土的施工技术 [J].智能城市,2017,3(07):260.

[3]刘维荃. 大坝施工中水下混凝土施工技术之研究 [J]. 农业开发与装备,2018,(11):71-72. 